\title{
MitoTEMPO Increases the Gastrointestinal Motility in Aged Rats
}

\author{
Emine Koc̣' (i), Yusuf Olgar² (i), Belma Turan² \\ 'Department of Physiology, Near East University School of Medicine, Nicosia, Cyprus \\ ${ }^{2}$ Department of Biophysics, Ankara University School of Medicine, Ankara, Turkey
}

ORCID IDs of the authors: E.K. 0000-000I-8804-4937; Y.O. 0000-0002-3226-745.

Cite this article as: Koc̣ E, Olgar Y, Turan B. MitoTEMPO Increases the Gastrointestinal Motility in Aged Rats. Cyprus J Med Sci 2019; 4(I): 24-7.

\section{BACKGROUND/AIMS}

During the process of aging, many physiological functions in organs change. Mitochondria play an important role in aging. In addition, there are several important gastrointestinal system dysfunction and intestinal problems occur in aging. The aim of this study is to examine how aging affects the gastrointestinal motility and to investigate the effects of the (2-(2,2,6,6-Tetramethylpiperidin-I-oxyl-4-ylamino)-2oxoethyl) triphenylphosphonium chloride monohydrate (mitoTEMPO) in adult and aged rats' gastrointestinal contractility, on the isolated ileal and duodenal segments.

\section{MATERIAL and METHODS}

In this work, 24-month old male was used as aged-rats and was compared with those of 6-month old as adult-rats. The isolated duodenal and ileal segments were suspended in isolated tissue-bath. The contractile responses induced with acetylcholine (ACh) and the relaxation responses induced with phenylephrine were recorded. In order to study the effects of mito-TEMPO, the segments were incubated for one hour with I $\mu \mathrm{m}$ mito-TEMPO and the responses of acetylcholine and phenylephrine were recorded.

\section{RESULTS}

The results indicate that the responses of the ACh-induced contraction were significantly lower in aged rats as compared to adult animals in the ileal and duodenal segments, and phenylephrine-induced relaxations were higher in the duodenal segments.

\section{CONCLUSION}

Treatment with the antioxidant mitoTEMPO has significantly affected the responses to the ACh-induced contraction and phenylephrineinduced relaxation that occurs with aging.

Keywords: Aging-contraction, aging-relaxation, mitoTEMPO, isolated ileum, isolated duodenum

\section{INTRODUCTION}

Aging is one of the greatest risk factors for many organ dysfunctions and physiological functions in organs and tissues. Thus, the number of nerve cells in the human colon decreases with age (I). The time for food to pass through the colon is prolonged in aged rats, and therefore the colonic motility may be also affected by aging (2). Reports imply that more frequent chronic functional constipation in elderly people has been observed (3). In aging, the gradual loss of the $\mathrm{Ca}^{+2}$ balance in cells alters cellular physiological functions $(4,5)$. Reports showed that during aging, there was a decrease in the $\mathrm{Ca}^{+2}$ release according to $\mathrm{Ca}^{+2}$-induction (6) in addition to nitric oxide, the most vital mediator in the longitudinal muscle of young individuals, which losses its significance with aging (7).Mitochondria are exposed to oxidative stress, which is involved in the normal aging process. Under pathological conditions, reactive oxygen species are over produced by the mitochondrial electron-transport chain uncoupling, the activation of the xanthine-oxidoreductase system, or by excessive stimulation of the NAD $(P) H$, which can overwhelm the endogenous antioxidant defense mechanisms (8). However, the role of mitochondrial dysfunction still remains unclear (9).

The mitoTEMPO has been used as an antioxidant. It is a nitroxide, conjugated to a triphenylphosphonium moiety, which is mitochondrion targeted. As nitroxides are the superoxide-dismutase mimetics, mitoTEMPO could act as a mitochondrial superoxide scavenger and therefore protect mitochondria from the age-induced oxidative damage (IO). Previous studies showed that mitoTEMPO lowers mitochondrial superoxide levels and increases the survival rate in septic mice (II). 
In this work, we report that aging might have been associated with the reduction of the contractile effects of acetylcholine and relaxation effects of phenylephrine in isolated ileal and duodenal segments.

\section{MATERIALSAND METHODS}

This study has received the approval by the local ethics committee of Ankara University (reference number, 2016-18-165). Healthy adult male Wistar rats ( $150-250 \mathrm{~g}$ ) were housed under standard conditions. Two experimental sets were designed. The first set of animals was 6 month old ( 10 male rats weighing $340 \pm \mathrm{lg}$ ) and was considered the adult set. The second experimental set was 24 months old ( 10 male rats weighing $350 \pm 8 \mathrm{~g}$ ), and it was considered the aged set. The blood glucose level of the adult group compared to the aged group was $80.5 \pm 1.4 \mathrm{mg} / \mathrm{dL}$ and $83.9 \pm 2.5$ $\mathrm{mg} / \mathrm{dL}$, respectively.

Pentobarbital (30 mg/ kg intraperitoneally) was used for anesthetizing. The ileum and duodenum segments (0.3-0.5-mm-long pieces) were removed. Then, the tissue segments were suspended in an isolated tissue bath containing $15 \mathrm{~mL}$ of the Krebs-Henseleit solution ( $\mathrm{mM} \mathrm{NaCl}$ II8, $\mathrm{KCl} 4.7, \mathrm{CaCl}_{2} 2.5, \mathrm{KH}_{2} \mathrm{PO}_{4}$ I.2, $\mathrm{NaHCO}_{3} 25$, $\mathrm{MgSO}_{4} \mathrm{I.2}$ and glucose II.I), and a $95 \% \mathrm{O}_{2}, 5 \% \mathrm{CO}_{2}$ mixture at $37^{\circ} \mathrm{C}$, $\mathrm{pH} 7.4$, was passed into the solution. The segments were brought into equilibrium for $60 \mathrm{~min}$ under an optimal resting tension of

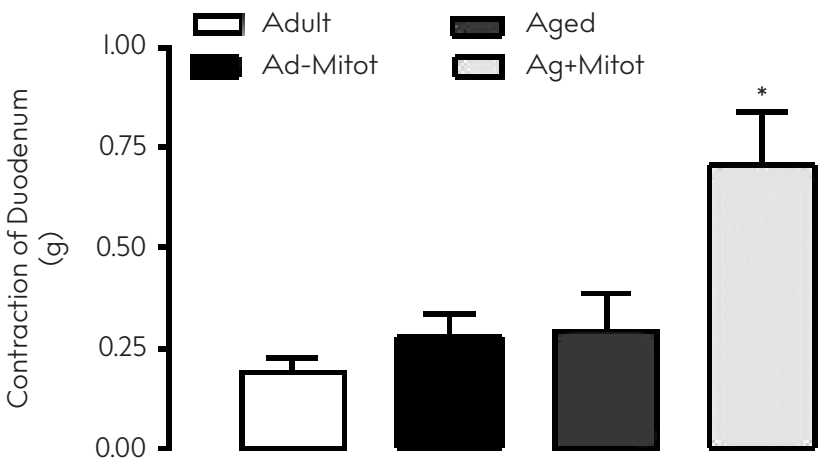

FIGURE I. Effects of mitoTEMPO on the ACh-induced contraction in an adult and aged isolated duodenum segments. Data are presented as the mean \pm standard error of mean.

$\mathrm{N}=8-12,{ }^{*} p<0.05$ vs. aged

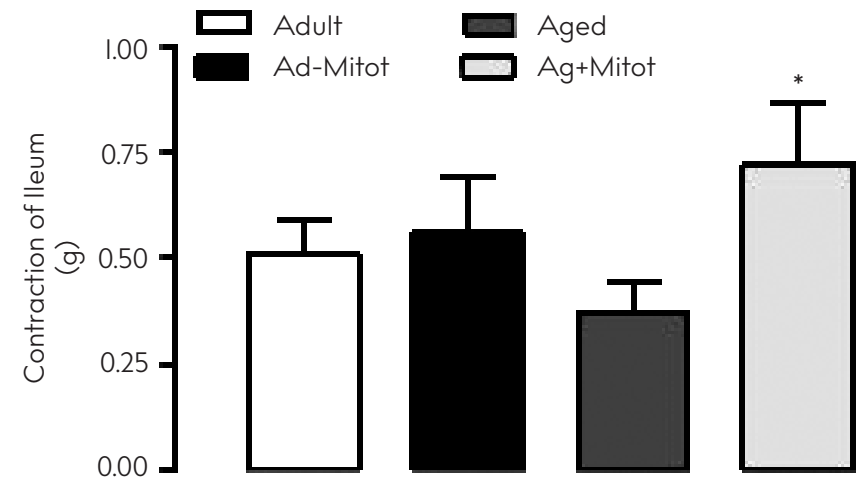

FIGURE 2. Effects of mitoTEMPO on the ACh-induced contraction in an adult and aged isolated ileum segment. Data are presented as the mean \pm standard error of mean

$N=8$ for each group. ${ }^{*} p<0.05$ vs, aged
Ig. After equilibration, the ileum and duodenum segments were contracted with acetylcholine $(\mathrm{ACh})\left(\mathrm{IO}^{-4}-10^{-7}, 6 \mathrm{M}\right)$ and relaxed with phenylephrine $\left(10^{-4}-10^{-7}, 6 \mathrm{M}\right)$. These doses were considered as maximal doses, after the cumulative addition of $\mathrm{ACh}$ and phenylephrine into the control group. Contraction and relaxation changes were recorded in the isometric tension recorder on the Biopac version 3.7.0. Then, mitoTEMPO (SML 0737, Sigma) was added into the perfusion medium. The isolated ileal and duodenal segments were incubated for I $h$ in the medium, and then the contraction and relaxation responses were recorded.

Statistical analyses were performed with an unpaired t-test. Significance values were accepted as ${ }^{*} p<0.05 \mathrm{vs}$. adult and $p<0.05$ vs. aged. Values were presented as mean \pm standard error of mean.

\section{RESULTS}

The effects of mitoTEMPO on the gastrointestinal contractility of the isolated ileal and duodenal segments of adult and aged rats were examined.

From Figure I, it can be observed that no significant differences between the responses of the $\mathrm{ACh}$-induced contractions in the adult and aged duodenal segments were found. When the adult and aged duodenal segments were incubated with mitoTEM-

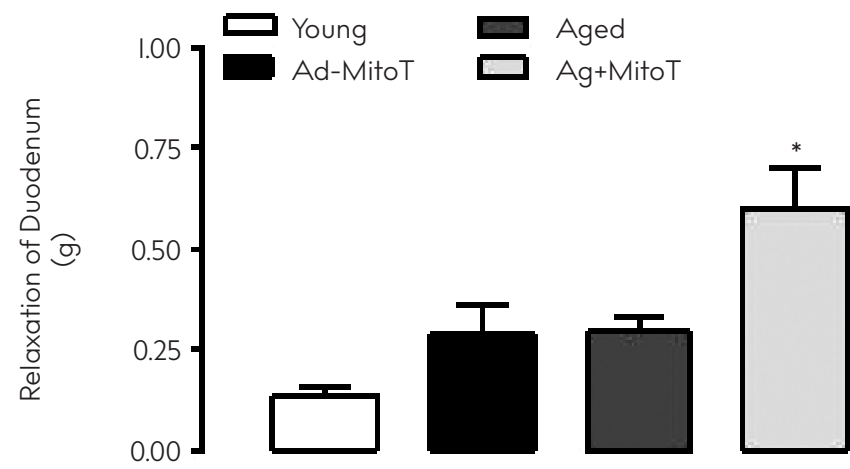

FIGURE 3. Effects of mitoTEMPO on the phenylephrine-induced relaxation in an adult and aged isolated duodenum segment. Data are presented as the mean \pm standard error of mean $\mathrm{N}=7-10,{ }^{*} p<0.05$ vs. aged

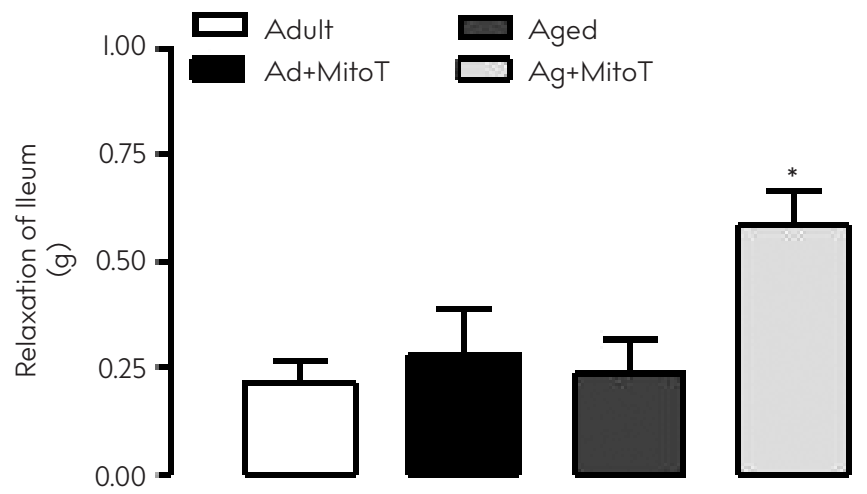

FIGURE 4. Effects of mitoTEMPO on the phenylephrine-induced relaxation in an adult and aged isolated ileum segment. Data are presented as the mean \pm standard error of mean

$\mathrm{N}=7$ for each group, ${ }^{*}<<0.05 \mathrm{vs}$. aged 
$\mathrm{PO}$, significant increases in aged-doudenal $\mathrm{ACh}$-induced contractions compared to adult rats were observed.

When comparing the $\mathrm{ACh}$-induced contraction of the ileal segments of adult and aged rats, it was shown that the responses of adult ileal segments were higher when compared to the aged rats. When the adult and aged ileal segments were incubated with mitoTEMPO, the responses of the ACh-induced contractions in aged ileal segments were significantly higher when compared to the adult segments, as shown in Figure 2.

Figure 3 shows that the responses of the phenylephrine-induced relaxations were lower in adult duodenal segments compared to the aged duodenal segments. When the adult and aged duodenal segments were incubated with mitoTEMPO, the responses of phenylephrine-induced relaxation in aged ileal segments were significantly higher when compared to the adult duodenal segments.

As shown in Figure 4, the responses of the phenylephrine-induced relaxations were similar in adult and aged ileal segments. But when the ileal segments were incubated with the mitoTEM$\mathrm{PO}$, the values were significantly higher in the aged ileal segments when compared to the adult ileal phenylephrine-induced relaxations.

\section{DISCUSSION}

The effects of mitoTEMPO on the contractility of adult and aged isolated ileal and duodenal segments in rats were investigated in this study. Our results indicate that the contractility in the aged group decreased and that the relaxation was greater than in the adult group. The results also showed that with the incubation for I $h$ with mitoTEMPO, ileal and duodenal contractility increased significantly in aged rats.

Acetylcholine is an important neurotransmitter, and it induces the contraction in the gastrointestinal tract. Our results showed that the ACh-induced contraction decreased in aged rats; however, these data conflict with Tezuka et al. (12) who report that the contractile response to acetylcholine has no effect on the jejunum and colon in aged rats.

The processes of aging are not well defined. More than 300 theories have been introduced since Medvedev, but none was accepted (13). In 1954, the free-radical theory of aging was proposed by Harman who stated that "aging results from imperfect protection against tissue damage by free radicals in addition to factors like genetic, activity, nutrition and temperature." Despite many investigations on the relationship between lipid peroxidation and aging, the results were conflicting because aging changes are small early in life but increase quickly with age (14). However, many investigators have accepted that biological aging is the failure of an organism to maintain homeostasis (15). In aging of the submucous plexus of the jejunum-ileum, there is a loss of $38 \%$ of the neurons, which is probably due to degenerated mitochondria in old animals (16). However, histological experiments carried out by Lee et al. (17) reported that during aging, a significant loss in the thickness of the intestinal mucosa is accompanied by higher reactive species.

In this work, 24-month-old animals were used and showed that contractility in the ileum decreased. According to reports, ag- ing is characterized by a decrease in glutathione concentrations and an increase in the oxidation of protein with a decrease in the mitochondrial NO content in 28-month-old rats (18). During the aging process, the oxidative stress takes place, and endogenously produced oxidants in the cells are usually increased ( $I 9$, 20).

Lopes et al. (4) reported that the activation of muscarinic receptors induces more contractions in aged rats than in adult animals, which conflicts with our data. They showed that the changes in intracellular $\mathrm{Ca}^{2+}$ stores affect contraction and may cause dysfunction during the cell-aging damage.

In aging, several aspects of $\mathrm{Ca}^{2+}$ homeostasis might be affect$\mathrm{ed}$, such as the $\mathrm{Ca}^{2+}$ influx, release of $\mathrm{Ca}^{2+}$ from stores, and $\mathrm{Ca}^{2+}$ uptake process by the sarcoplasmic reticulum and mitochondria (21). It is unknown whether similar changes occur in the gastrointestinal system. Although functional and structural changes are known to occur in many functions, the mechanisms responsible for these changes are unclear. Many investigators claimed that the oxidant stress increases, due to an elevated reactive oxygen, species production, or to decrease the function of natural antioxidant pathways (22-24).

mitoTEMPO was used as the antioxidant factor in our experiments. Mitochondria are the most important sources of reactive oxygen species in the body. We assumed that the therapeutic inhibition of mitochondria by a mitochondrial targeted antioxidant mitoTEMPO might be beneficial in the setting of the gastrointestinal dysmotility. mitoTEMPO is a physicochemical compound that has the ability to pass through lipid bilayers easily and accumulate in the mitochondria selectively (10). Both in vitro and in vivo studies have confirmed that mitoTEMPO is a mitochondria-targeted antioxidant with superoxide and alkyl radical scavenger properties $(10,25)$. It is unknown if there are any off-target effects of mitoTEMPO when it is accumulated in mitochondria, and it is also unclear how much of mitoTEMPO has actually gone to the organs (26).

In this study, we have also demonstrated that therapeutic inhibition of mitochondrial ROS using mitoTEMPO prevented oxidative stress and reduced the gastrointestinal dysmotility in aged animals. Our data strongly indicated that mitochondria-targeted antioxidants have therapeutic effects on aged-related dysmotility; thus, a form of antioxidant therapy such as mitoTEMPO may be useful for treating age-related gastrointestinal dysmotility. To the best of our knowledge, this study is the first to demonstrate that antioxidant treatment, such as mitoTEM$\mathrm{PO}$, can significantly reverse the response to acetylcholine and phenylephrine in isolated gastrointestinal segments in aged rats.

In conclusion, we demonstrated that the treatment with the antioxidant mitoTEMPO can significantly affect the responses to the ACh-induced contractions and phenylephrine-induced relaxations that occur with aging. The results are consistent with the hypothesis over the production of ROS with aging.

Ethics Committee Approval: Ethics committee approval was received for this study from the Ethics Committee of Ankara University School of Medicine (Approval Date: 2016, Approval Number: 18-165). 
Informed Consent: N/A.

Peer-review: Externally peer-reviewed.

Author contributions: Concept - E.K., B.T., Y.O.; Design - E.K., B.T., Y.O.; Supervision - B.T., Y.O.; Resource - B.T., Y.O.; Materials - B.T., Y.O.; Data Collection and/or Processing - E.K., Y.O.; Analysis and/or Interpretation - Y.O.; Literature Search - E.K., B.T.; Writing - E.K., B.T., Y.O.; Critical Reviews - E.K., B.T., Y.O.

Conflict of Interest: The authors have no conflicts of interest to declare.

Financial Disclosure: The authors declared that this study has received no financial support.

\section{REFERENCES}

I. Gomes OA, Souz RR, Liberti EA. A preliminary investigation of the effects of aging on nerve cell number in the myenteric ganglia of the human colon. Gerontology 1997; 43: 210-7. [CrossRef]

2. McDougal JN, Miller MS, Burks TF, Kreulen DL. Aged-related changes in colonic function in rats. Am J Physiol 1984; 247: G542-6. [CrossRef]

3. Vestal RE. Drug use in elderly: a review of problems and special considerations. Drugs 1978; 16: 358-82. [CrossRef]

4. Lopes GS, Ferreira AT, Oshiro ME, Vladimirova I, Jurkiewicz NH, Jurkiewicz $A$, et al. Aging-related changes of intracxellular $\mathrm{Ca}$ stores and contractile response of intestinal smooth muscle. Exp Gerontol 2006; 41: 55-62. [CrossRef]

5. Shen B, Zhu J, Zhang J, Jiang F, Wang Z, Zhang Y, et al. Attenuated mesengial cell proliferation related to store-operated Ca+ entry in aged rat: the role of STIM I and orai I. Age (Dordr) 2013; 35: 2193-202. [CrossRef]

6. Durlu-Kandilci T, Denaizatı M, Șahin-Erdemli I. Aging changes agonist induced contractile responses in permeabilized rat bladder. Age (Dordr) 2015; 37: 9807. [CrossRef]

7. Takeuchi T, Niioka S, Yamaii M, Okishio Y, Ishii T, Nishio Y, et al. Decrease in participation of nitric oxide in nonadrenergic, noncholinergic relaxation of rat intestine with age. Jpn J Pharmacol 1998; 78: 293-302. [CrossRef]

8. Kawanishi S, Oikawa S. Mechanism of telemore shortening by oxidative stress. Ann N Y Acad Sci 2004; 1019: 278-84. [CrossRef]

9. Wang $Y$, Hekimi S. Mitochondrial dysfunction and longevity: untangling the knot. Science 2015; 350: 1204-7. [CrossRef]

10. DikalovaAE, Bikineveya AT, Budyzn K, nazarewicz RR, McCann L, Lewis $W$, et al. Therapeutic targeting of mitochondrial superoxide in hypertension. Circ Res 2010; 107: 106-16. [CrossRef]

II. Patil NK, parajuli N, Mac-Millan-Crow LA, Mayeux PR. Inactivation of renal mitochondrial respiratory complexes and manganese superoxide dismutase during sepsis: mitochondria-targeted antioxidant mitigates injury. Am J Physiol Renal Physiol 2014; 306: F734-43. [CrossRef]
12. Tezuka A, Ishiata A, Aita T, Katano Y. Aging-related alteration in the contractile responses to acetylcholine, muscarinic cholinoceptors and cholinesterase activities in jejunum and colon of the male Fischer 344 rats. Exp Gerontol 2004; 39: 91-100. [CrossRef]

13. Menvedev Z. An attempt at rational classification of theories of aging. Biol Rev Camb Philos Soc 1990; 65: 375-98. [CrossRef]

14. Kasapoğlu M, Özben T. Alteration of antioxidant enzymes and oxidative stress markers in aging. Exp Gerontol 200I; 36, 2: 209-20. [CrossRef]

15. Gutteridge JMC. Aging and free radicals. Med Lab Sci 1992; 49: 313-8.

16. Zanesco MC, Souza RR. Morphoquantative study of the submucous plexus (of meissner) of the jejunum-ileum of young and old quinea pig. Arq Neuropsiquiatr 20Il; 69: 85-90. [CrossRef]

17. Lee EK, Jung KJ, Choi J, Kim HJ, Han YK, Jeong YS, et al. Molecular basis for age-related changes in ileum: Involment of Bax-caspase-dependent mitochondrial apoptotic signaling. Exp Gerontol 2010; 45: 970-6. [CrossRef]

18. Grattagliano I, Portincasa P, Cocco T, Moschetta A, Di paola M, Palmieri $\mathrm{Vo}$, et al. Effect of dietary restriction and $\mathrm{N}$-acetylcysteine supplementation on intestinal mucosa and liver mitochondrial redox status and function in aged rats. Exp Gerontol 2004; 39: 1323-32. [CrossRef]

19. Helmy MM. Potential hepato-protective effect of alfa-tocopherol or simvastatin in aged rats. Pharmacol Rep 2012; 64: 698-705. [CrossRef]

20. Xu J, Rong S, Xsie B, Sun Z, Zhang L, Wu H., et al. Porcyanidinsaxtracted from the lotus seedpod ameliorate ade-related antioxidant deficit in aged rats. J Gerontol A Biol Sci Med Sci 20I0; 65: 236-4l. [CrossRef]

21. Lopes GS, Ferreira AT, Oshiro ME, Vladimirova I, Jurkiewicz NH, Jurkiewicz A, Smaili SS. Aging-related changes of intracxellular Ca stores and contractile response of intestinal smooth muscle. Exp Gerontol 2006; 41: 55-62. [CrossRef]

22. Sun D, Huan A, Yan EH, Wu Z,Yan C, Kaminsky PM, et al. Reduced release of nitric oxide to shear stressin mesenteric arteries of aged rats. Am J Physiol Heart Circ Physiol 2004; 286: H2249-56. [CrossRef]

23. Briones AM, Montoya N,Giraldo I, Villa E. Aging affects nitric oxide synthase, cyclooxigenase and oxidative stress enzymes expression differently in mesenteric resistance arteries. Auton Autacoid Pharmacol 2005; 25: 155-62. [CrossRef]

24. Hamilton CA, Brosnan MJ, Mcintyre M, Graham D, DominiczakAF. Superoxideexess in hypertension and aging:a common cause of endothelial dysfunction. Hypertension 2001; 37: 529-34. [CrossRef]

25. Liu M, Liu H, Dudly SC Jr. Reactive oxygen species originating from mitochondria regulate the cardiac sodium channel. Circ Res 2010; 107: 967-74. [CrossRef]

26. Ni R, Cao T, Xiong S, Ma J, Fan GC, Lacefield JC, et al. Therapeutic inhibition of mitochondrial reactive oxygen species with mito-TEMPO reduces diabetic cardiomiyopathy. Free Radic Biol Med 2016; 90 : 12-23. [CrossRef] 